\title{
The importance and relevance of peak bone mass in the prevalence of osteoporosis
}

\author{
Jean-Philippe Bonjour, MD,(I) Thierry Chevalley, MD, (I) Serge Ferrari, MD,(I) René Rizzoli, MD.(I)
}

\author{
Bonjour JP, Chevalley T, Ferrari S, Rizzoli R. \\ The importance and relevance of peak bone mass \\ in the prevalence of osteoporosis. \\ Salud Publica Mex 2009;5 I suppl I:S5-SI7.
}

\begin{abstract}
Bone mass and strength achieved at the end of the growth period, simply designated as "Peak Bone Mass (PBM)", plays an essential role in the risk of osteoporotic fractures occurring in adulthood. It is considered that an increase of PBM by one standard deviation would reduce the fracture risk by $50 \%$.As estimated from twin studies, genetics is the major determinant of PBM, accounting for about 60 to $80 \%$ of its variance. During pubertal maturation, the size of the bone increases whereas the volumetric bone mineral density remains constant in both genders. At the end of puberty, the sex difference is essentially due to a greater bone size in male than female subjects. This is achieved by larger periosteal deposition in boys, thus conferring at PBM a better resistance to mechanical forces in men than in women. Sex hormones and the IGF-I system are implicated in the bone sexual dimorphism occurring during pubertal maturation. The genetically determined trajectory of bone mass development can be modulated to a certain extent by modifiable environmental factors, particularly physical activity, calcium and protein intakes. Prepuberty appears to be an opportune time to modify environmental factors that impinge on bone mineral mass acquisition.
\end{abstract}

Key words: bone growth; peak bone mass; genetic determinants; sex hormones; IGF-I; physical activity; calcium intake; protein intake
Bonjour JP, Chevalley T, Ferrari S, Rizzoli R. Importancia y relevancia de la masa ósea máxima en la prevalencia de osteoporosis.

Salud Publica Mex 2009;5 I supI I:S5-SI7.

\section{Resumen}

La masa y fortaleza ósea conseguida al final del periodo de crecimiento, designada simplemente como masa ósea máxima (MOM), constituye un factor crítico en cuanto al riesgo de fracturas osteoporóticas en la edad adulta. Se considera que un aumento de MOM de una desviación estándar reduciría el riesgo de fracturas en 50 por ciento. Los estudios en gemelos han mostrado que la genética es el principal determinante de MOM, siendo responsable de 60 a $80 \%$ de su variación. Durante la maduración puberal el tamaño de los huesos aumenta mientras que su densidad mineral volumétrica permanece constante en ambos géneros. Al final de la pubertad la diferenciación sexual se debe básicamente al mayor tamaño de los huesos en hombres que en mujeres. Esto se consigue mediante una mayor deposición periosteal en los muchachos, confiriéndole así a la MOM mayor resistencia a las fuerzas mecánicas en hombres que en mujeres. Este dimorfismo sexual óseo que se presenta durante la maduración puberal se debe sobre todo a las hormonas sexuales y al factor de crecimiento insulínco I (IGF-I). La trayectoria genéticamente determinada de desarrollo de la masa ósea puede modularse hasta cierto punto mediante factores ambientales modificables, sobre todo la actividad física y la ingesta de calcio y proteínas. El periodo prepuberal parece ser el momento oportuno para modificar los factores ambientales que afectan la adquisición de masa mineral ósea.

Palabras clave: crecimiento óseo; masa ósea máxima; determinantes genéticos; hormonas sexuales; factor de crecimiento insulínco I (IGF-I); actividad motora; ingesta de calcio; ingesta de proteínas

(I) Service of Bone Diseases, Department of Rehabilitation and Geriatrics, Geneva University Hospital, Geneva, Switzerland. WHO Collaborating Center for Osteoporosis Prevention

Received on: January 7,2008 • Accepted on: March 7, 2008

Address reprint requests to: Professor Jean-Philippe Bonjour. Service of Bone Diseases, University Hospital. Rue Micheli-du-Crest 24. I2II Geneva I4, Switzerland E-mail:Jean-Philippe.Bonjour@medecine.unige.ch 
This his review deals with the development of bone mineral mass and strength in conditions of good health. The notions are essentially presented in relation with the risk of adult osteoporosis. The review does not cover any diagnostic or therapeutic aspects of pediatric bone diseases.

In the first part of the review we present the main characteristics of bone mass and strength acquisition from birth to maturity. Then, we analyze the basis upon which one can consider that the bone mass and strength acquired by the end of the growth period pertains to the risk of fragility fractures that exponentially increase in both women and men in the second half of adult life. The last part of the review deals with the contribution in the development of bone mass and strength of genetic, endocrine, mechanical and nutritional factors.

\section{Characteristics of bone mass and strength acquisition}

Assessment. Several structural elements determine the mechanical strength of bone. The size of the bone, the amount of bony tissue within the periosteal envelope and its spatial distribution, i.e. the micro- and macroarchitecture, and the degree of mineralization and structural organization of the organic matrix are the most important elements that determine the resistance to mechanical loading. In each individual, these components as a whole follow a trajectory from the intrauterine life to completion of the skeletal growth process, i.e. at the attainment of peak bone mass (PBM). To date, the areal bone mineral density $\left(\mathrm{aBMD}\right.$ in $\left.\mathrm{g} / \mathrm{cm}^{2}\right)$, as it can be assessed by dual X-Ray absorptiometry (DXA), is the most common variable studied during infancy, childhood and adolescence. There are several explanations for the widespread use of aBMD measurement to study bone acquisition during growth in relation to the risk of osteoporosis in adulthood. Determination of aBMD is particularly convenient in terms of availability of equipment, low exposure to irradiation, reproducibility of the measurement at several sites of the skeleton and, last but not least, its relationship with adult osteoporosis fracture risk as adequately documented in large cohorts of women and men. Because of this last characteristic, aBMD was recognized by several national and international institutions including the World Health Organization (WHO), ${ }_{1}^{1}$ as the variable to be measured for establishing the diagnosis of adult osteoporosis. These positive aspects do not mean that aBMD measurement integrates all determinants of bone strength. Structural and functional components contribute to the degree of bone fragility and therefore to the risk of experiencing osteoporotic fractures during adult life. The recent use of high-resolution peripheral quantitative computed tomography (pQCT) can provide additional information on more subtle bone structural mechanical resistance components. This technical approach is expected to improve the prediction of bone strength as compared to the current use of the variables that can easily be captured by DXA: aBMD, bone mineral content (BMC), and the bone size of the region of interest. In addition, at some skeletal sites an estimate of volumetric (v)BMD, cortical thickness, cross-sectional area and moment of inertia can be computed.

Quantitative ultrasonography (QUS) has been compared to DXA for identifying adults with osteoporosis and fragility fractures. Although QUS parameters determined in some but not all tested devices can predict the osteoporotic fracture risk, their use is still not recommended for the diagnosis or treatment monitoring of adult osteoporosis. ${ }^{2}$ The application of QUS technology in pediatric populations is attractive because of several characteristics including absence of ionizing radiation, portability and low cost. Calcaneous QUS measurements can detect low bone mass during childhood and adolescence. However, as recently argued, this technique remains a research tool in the pediatric population. $^{3}$

Structural development. During growth, aBMD increment is essentially due to an increase in bone size, ${ }^{4}$ which is closely linked to a virtually commensurate increment in the amount of mineralized tissue contained within the periosteal envelope. Consequently, vBMD increases very little from infancy to the end of the growth period.

In healthy girls, longitudinal examination of the lumbar spine development during pubertal maturation indicates that the standard deviation scores (Z-scores) of aBMD, BMC, vBMD, as well as vertebral body width and height are highly correlated, with " $\mathrm{r}$ " coefficients ranging from 0.70 to 0.82 , as compared to 0.85 for standing height. ${ }^{5}$

Before puberty, no substantial gender difference has been reported in bone mass of the axial (lumbar spine) or appendicular (e.g. radius and femur) skeleton when adjusted for age, nutrition and physical activity. There is no evidence of a gender difference in bone mass at birth; the vBMD appears to be similar in female and male newborns. This absence of substantial sex differences in bone mass is maintained until the onset of pubertal maturation. The gender difference in bone mass is expressed during puberty. This difference appears to be due mainly to a more prolonged bone maturation period in males than in females, with a larger resulting increase in bone size and cortical thickness. Puberty affects bone size much more than it does vBMD. There is no significant sex difference in volumetric trabecular density at the end 
of pubertal maturation. ${ }^{4,6,7}$ Bone mass accumulation rate at both lumbar spine and femoral neck levels increases 4 to 6-fold over a 3- and 4-year period in females and males, respectively. The increment in bone mass gain is less marked in long bone diaphyses. ${ }^{8}$

In the lumbar spine, the gender difference observed when PBM is attained consists essentially of a greater vertebral body diameter in the frontal plane of males as compared to females. ${ }^{9}$ This gender-related structural dimorphism does not attenuate with ageing. It certainly represents an important macro-architectural determinant of the difference in the incidence of vertebral fragility fractures observed between female and male subjects in later life. Within each gender, this structural property also plays an important role in vertebral fracture risk. In postmenopausal women, a smaller cross-sectional area of vertebral bodies was measured in those with than without vertebral fractures despite the fact that the two groups displayed equally low trabecular vBMD as determined by spinal QCT. ${ }^{10}$

The gender difference in either aBMD or BMC observed in the radial or femoral diaphysis once PBM is attained also appears to be essentially due to a greater gain in bone size in males than females during pubertal maturation. A recent study comparing bone variables (BMC, aBMD and vBMD) in opposite-sex twins corroborates this notion. ${ }^{11}$

Transient fragility. There is an asynchrony between the gain in standing height and the growth of bone mineral mass during pubertal maturation. ${ }^{8,12}$ This phenomenon may be responsible for the occurrence of a transient bone fragility in adolescence that may contribute to the higher incidence of fractures that occurs when the dissociation is maximal between the rates of standing height and mineral mass accrual. ${ }^{13,14}$ Nevertheless, some trauma fractures observed during childhood or adolescence may be unrelated to transient bone fragility that occurs at peak height velocity during the peripubertal growth phase. It is possible that some of these fractures may also be determined by tracking, from infancy to the end of skeletal maturation, along a relatively low bone mass percentile (Z-score) ${ }^{15}$ Thus, the deficit would be permanent and expressed by a relatively low PBM and increased risk of fragility fracture in later adult life. ${ }^{16}$ Time of peak bone mass attainment. In adolescent females, gain in bone mass declines rapidly after menarche; no further statistical gains are observed 2 years later at least in sites such as the lumbar spine or femoral neck. In adolescent males, the gain in BMD or BMC that is accelerated particularly from 13-17 years declines markedly thereafter, although it remains significant between 17-20 yrs in both lumbar spine BMD and BMC and in midfemoral shaft BMD; in contrast, no significant in- crease is observed for femoral neck BMD. ${ }^{8}$ In subjects who reached pubertal stage P5 and grew less than 1 $\mathrm{cm} / \mathrm{yr}$, a significant bone mass gain persisted in males but not in females. ${ }^{8}$ This suggests the existence of an important sex difference in the magnitude and / or duration of the so-called "consolidation" phenomenon that contributes to PBM.

As described above the change in vBMD during growth is very modest as compared to the increment in bone size. Furthermore the increased vBMD as measured by QCT has been detected in vertebral cancellous bone but not in appendicular cortical tissue. ${ }^{6}$ In the lumbar vertebral body, no difference is observed between the mean values of 16 year-old and 30 year-old subjects. ${ }^{17}$ This observation supports the notion that the modest increase in vertebral trabecular vBMD is achieved soon after menarche. This is in keeping with numerous observations indicating that at most skeletal sites, total bone mineral mass does not significantly increase from the third to the fifth decade. Nevertheless, a few crosssectional studies suggest that bone mass acquisition may still be substantial during the third and fourth decades. In any case, the balance of published data does not sustain the concept that bone mass at any skeletal site, in either gender and in any ethnic geographic population group, continues to accumulate through the fourth decade. $^{4}$

\section{Importance of peak bone mass}

The relative contribution of peak bone mass to fracture risk has been explored by examining the variability of aBMD individual values in relation with age. If PBM was relatively unimportant in the determination of $\mathrm{aBMD}$ and fracture risk in later life, one would expect an enlargement of the range of aBMD values with aging. However, several observations are not consistent with such an increased range in aBMD values in relation to age. In untreated post-menopausal women, the standard deviation (SD) of bone mineral mass measured at both the proximal and distal radius was not greater in women aged 70 to 75 compared to 55 to 59 years. ${ }^{18}$ Similar findings were reported at two other clinically relevant skeletal sites at risk of osteoporotic fractures. Thus, at both the lumbar spine and femoral neck, the range of aBMD values was no wider in women aged 70 to 90 years old than in women aged 20 to 30 years. ${ }^{19}$ This constant range of individual aBMD values was observed despite the marked reduction in spine and femoral neck aBMD values in the older women. ${ }^{19}$

In agreement with these cross-sectional findings, a longitudinal study of women ranging in age from 20 to 94 years (median age 60 years), with follow-up periods 
as long as 22 years, showed that the average annual rate of bone loss was relatively constant and tracked well within one person..$^{20}$ High correlations $(r=0.80)$ were observed between the baseline aBMD values and those obtained after 22 years of follow-up..$^{20}$ This tracking pattern of aBMD, which is already observed during growth, would appear to persist over six decades of adult life. The notion of 'tracking' has two important implications. First, the prediction of fracture risk based on one single measurement of femoral neck aBMD remains reliable in the long term..$^{20}$ Second, within the large range of femoral neck aBMD values, little variation occurs during adult life in individual Z-scores or percentiles. From these two implications, it can be inferred that the bone mass acquired at the end of the growth period appears to be more important than the bone loss occuring during adult life.

In a mathematical model using several experimental variables to predict the relative influences of peak bone mass, menopause and age-related bone loss on the development of osteoporosis, ${ }^{21}$ it was calculated that an increase in peak bone mass of $10 \%$ would delay the onset of osteoporosis by 13 years. ${ }^{1}$ In comparison, a $10 \%$ increase in the age of menopause, or a $10 \%$ reduction in age-related (non-menopausal) bone loss would only delay the onset of osteoporosis by 2 years. ${ }^{21}$ Thus, this theoretical analysis indicates that peak bone mass could be the single most important factor for the prevention of osteoporosis later in life. ${ }^{21}$

There is also evidence that the risk of fracture after the sixth decade may be related to structural and biomechanical properties of the bone acquired during the first 2-3 decades of life. Duan et al. ${ }^{22}$ calculated the fracture risk index (FRI) of the vertebral bodies based on the ratio of the compressive load and strength in young and older adults ( $\sim 30$ to 70 years of age). Load was determined by upper body weight, height and the muscle moment arm, and bone strength estimated from the bone cross-sectional area (CSA) and vBMD. From young to older adulthood, this index increased more in women (Chinese and Caucasian) than men of the same ethnicity. ${ }^{22}$ However, the dispersion of CSA, vBMD and FRI values around the mean did not increase with age within a given sex in either the Chinese or the Caucasian ethnic groups, ${ }^{22}$ suggesting an important role of bone acquired prior to the age of 30 . Similar conclusion was reached concerning the construction of the femoral neck. ${ }^{23}$

The importance of maximizing PBM has also been estimated from the determination of the risk of experiencing an osteoporotic fracture in adulthood. From the results of epidemiological studies, it is possible to predict that a $10 \%$ increase (about 1SD) in PBM could reduce the risk of fracture by 50\% in women after the menopause. ${ }^{1,24,25}$ Together, these findings strengthen the notion that maximizing bone health during growth may represent an important strategy in the prevention of osteoporosis and fractures during ageing.

\section{Determinants of peak bone mass and strength}

Several interconnected factors influence bone mass accumulation during growth. These physiological determinants classically include heredity, vitamin D and bonetropic nutrients (calcium, proteins), endocrine factors (sex steroids, IGF-I, $\left.1.25(\mathrm{OH})_{2} \mathrm{D}\right)$, mechanical forces (physical activity, body weight) (figure 1). Quantitatively, the most prominent determinant appears to be genetically related.

\section{Heredity}

Mass Parent-offspring comparison studies reveal a significant relationship in the risk of osteoporosis within families, with apparent transmission from either mothers or fathers to their children. 5,26,27 The familial resemblance for bone mineral mass in mothers and daughters is expressed before the onset of pubertal maturation. ${ }^{5}$

Comparison in the degree of correlation between pairs of monozygotic versus dizygotic twins allows one to estimate the contribution of heritability to the variance of bone mineral mass more precisely. ${ }^{28}$ This computation suggests that heritability, i.e. the additive effects of genes, explains 60 to $80 \%$ of the variance of adult bone mineral mass. This "genetic effect" appears to be greater in skeletal sites such as the lumbar spine compared to the femoral neck. ${ }^{28}$ It is possible that mechanical factors (e.g. physical activity, body weight, muscle force) exert greater influence on the cortical component of the proximal femur than on the prevailing trabecular framework of vertebral bodies, thus explaining the relatively low heritability of femoral aBMD. Despite the strong impact of heritability on aBMD, environmental factors still play an important role since they may account for up to 20 to $40 \%$ of peak bone mass variance

Search for osteoporosis genes. Two main approaches have dominated the search for genetic factors that would influence bone acquisition and thereby modify the susceptibility to osteoporosis in later life. One approach is to search by genome-wide screening for loci flanked by DNA micro-satellite markers that would co-segregate with the phenotype of interest in a population of related individuals. The pedigrees investigated to date consist mainly of families with a member at either extreme of 


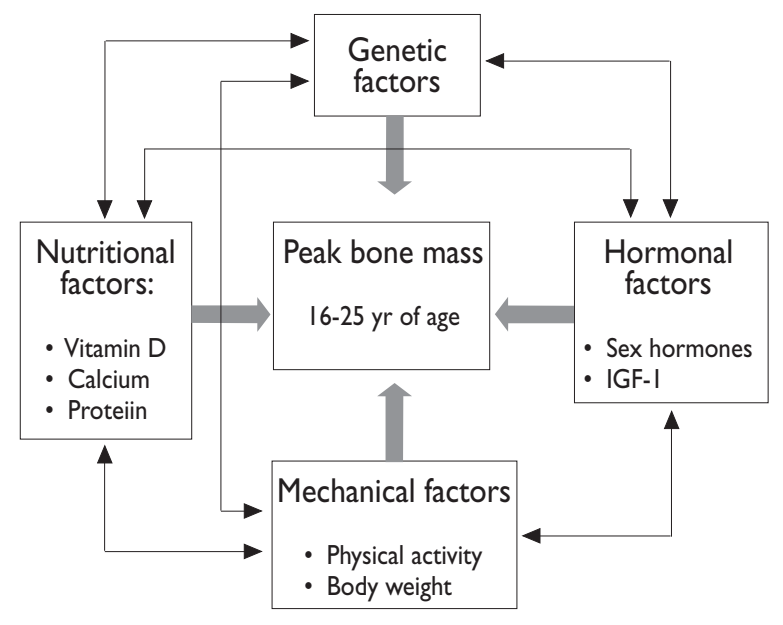

Figure I.Physiological determinants of PEAK bone MASS. THE BLACK ARROWS ILLUSTRATE THE INTERDEPENDENCY OF THE 4 TYPES OF FACTORS

the skeletal phenotype spectrum, particularly those exhibiting either very high or very low bone mineral mass or areal density. Genome screening for quantitative trait loci (QTLs) have also been used to detect within the "normal" population families and/or siblings with marked differences in bone mass, size or geometry. The second most frequently used approach is to search for an association between allelic variants or polymorphisms of genes coding for products that are implicated in bone acquisition or loss. Numerous polymorphisms of "candidate" genes have been found to be associated with $\mathrm{aBMD}$, so far the most convenient measurable surrogate of bone mass and strength. The genes studied code for molecules implicated in bone function and structure such as circulating endocrine factors, hormone receptors, local regulators of bone modeling and remodeling or matrix molecules. None of these genes appears to account for more than a few percent of PBM variance. See for review. ${ }^{28,30}$

Gene-environmement interactions in the skeletal response to nutrition and physical activity during growth is a difficult domain that remains to be approached by appropriate study designs. Identifying the implicated genes interacting with bone-specific nutrients and the response to mechanical loading represents a formidable, but hopefully not intractable, challenge. ${ }^{31}$

\section{Endocrine factors}

Sex hormones. As specified above, the development of bone mineral mass during the entire growth period, including during pubertal maturation, is essentially due to an increase in bone size, with very mild changes in the amount of mineralized tissue within the bone envelope. ${ }^{4,7,32,33}$ Likewise, once pubertal maturation has been reached, the gender difference in bone mass essentially results from a greater bone size increment in male subjects. $., 7,32,33$ In boys, the onset of puberty occurs later than in girls and the period of accelerated bone growth lasts for four as compared to three years in girls. ${ }^{8}$ These two characteristics probably account to a large extent for the gender difference in mean PBM observed in healthy young adults. ${ }^{4}$

An androgen receptor has been localized in growth plate chondrocytes in humans during pubertal maturation. ${ }^{32,33}$ However, there is no evidence that androgens stimulate longitudinal bone growth by a direct action on the skeleton. In adulthood, patients affected by the androgen insensitivity syndrome, with $X Y$ genotype and a marked female phenotype are taller than the average standing height of the corresponding female population. ${ }^{32,33}$ In contrast, it is well documented that estrogens play an essential role in longitudinal bone growth. They exert biphasic effects by accelerating bone growth at the beginning of puberty whereas in both genders, estrogens are key determinants for the closing of growth plates. ${ }^{7,33}$ During pubertal maturation, cross-sectional analysis of appendicular bone, at least in the upper limb, reveals some distinct gender dimorphism. In female subjects, bone mineral mass increases more by endosteal than periosteal accrual. ${ }^{34}$ In male subjects, the opposite structural modifications are observed with greater increases in periosteal than endosteal apposition resulting in the increment of both external and internal perimeters of the cortical structure. ${ }^{34}$ At the end of pubertal maturation, the cortical thickness is greater in male than female subjects. In vertebral bodies, the gender structural dimorphism is mainly expressed in the frontal axis, which is $10-15 \%$ larger in males than in females. ${ }^{9}$ These morphological differences in the geometry and mineral mass distribution of both axial and appendicular bones confer a greater mechanical resistance to loading of the male skeleton. To a large extent, they explain the greater risk of osteoporotic fractures occurring in adult women than men. The increased bone mineral apposition at the level of the endosteal surface during puberty in female subjects may teleologically represent a biological adaptation allowing the rapid mobilization of bone mineral in response to the increased needs during pregnancy and lactation.

A later age at menarche was found to be associated with lower aBMD in the spine and proximal femur ${ }^{35,36}$ and higher risk of vertebral ${ }^{37}$ and hip fracture ${ }^{38}$ in adulthood. Indirect evidence from a retrospective epidemiological survey suggests that this association is likely to 
be related to the influence of pubertal timing on PBM attainment. In premenopausal women, early compared to late menarche, is associated with higher aBMD. ${ }^{39,40}$ This association is usually considered as the expression of earlier and thereby longer exposure to estrogen. Although this intuitive explanation appears to be quite reasonable, there is no unequivocal evidence demonstrating that sex hormone exposure is the essential causal factor accounting for the association between pubertal timing and the risk of osteoporosis. ${ }^{16}$ A recent report also indicates that pubertal timing, as assessed in males by using age at peak height velocity, predicts fractures occurring before PBM attainment and aBMD in young adult men. ${ }^{41}$

In a prospective study in healthy girls with normal pubertal development, we observed a significantly greater proximal femur aBMD in those with mean menarcheal age of 12 as compared to 14 years. ${ }^{42}$ This study also suggested an interaction between the factors that trigger the onset of pubertal maturation and calcium intake. ${ }^{42}$ Whether calcium supplementation administered at the onset of pubertal maturation may influence the hypothalamic-pituitary-gonadal axis, by a leptin-dependent or -independent pathway, and thereby accelerate the occurrence of menarche remains an open question.

The growth hormone-insulin-like growth factor-1 system

From birth to the end of adolescence, the GH-IGF-1 system is essential for harmonious skeleton development. During puberty, the plasma level of IGF-1 rises transiently according to a pattern that is similar to the curve of the gain in bone mass and size. ${ }^{4}$ IGF-1 positively influences the growth in both length and width of the skeletal pieces. This factor exerts a direct action on both growth plate chondrocytes and osteogenic cells responsible for building both cortical and trabecular bone tissue constituents. This activity is also expressed by parallel changes in the circulating biochemical markers of bone formation, osteocalcin and alkaline phosphatase. In addition, IGF-1 exerts an important impact on renal endocrine and transport functions that are essential for bone mineral economy. IGF-1 receptors are localized in the renal tubular cells. They are connected to both the production machinery of the hormonal form of vitamin $\mathrm{D}$, namely $1,25(\mathrm{OH})_{2} \mathrm{D}$ and to the transport system of inorganic phosphate (Pi) localized in the luminal membrane of the tubular cells. By enhancing the production and circulating level of $1,25(\mathrm{OH})_{2} \mathrm{D}$, IGF-1 indirectly stimulates the intestinal absorption of $\mathrm{Ca}$ and $\mathrm{Pi}$ (figure 2). Coupled to the stimulation of the tubular capacity to reabsorb Pi, the extra cellular Ca-Pi product is increased by IGF-1, which, through this dual renal action, favors the mineralization of the bone matrix. Furthermore, at the bone level, IGF-1 still directly enhances the osteoblastic formation of the extra cellular matrix. In growth plate chondrocytes as well as in their plasma membrane derived extra cellular matrix vesicles are equipped by a phosphate transport system that plays a key role in the process of primary calcification and thereby in bone development. This Pi transport system is also present in other osteogenic cells ${ }^{43}$ and interestingly, is regulated by IGF-1. The hepatic production of IGF-1, which is the main source of its circulating level, is influenced not only by $\mathrm{GH}$, but also by other factors, particularly by amino acids from dietary proteins (figure 2).

During pubertal maturation, there is an interaction between sex steroids and the GH-IGF-1 system. The modalities of this interaction have still to be delineated in humans. From animal studies, relatively low concentrations of estrogens would appear to stimulate the hepatic production of IGF-1, whereas large concentrations apparently exert an inhibitory effect. ${ }^{33}$ Androgens would appear to act mainly at the pituitary level, but only after being converted into estrogens by the enzymatic activity of aromatase. ${ }^{33}$

\section{Mechanical factors}

Molecular pathways. Mechanical forces impinge on the skeleton by enhancing osteoblastic bone formation, while inhibiting osteoclastic bone resorption. ${ }^{44}$ The effect on osteoblast numbers and activity probably involve several local factors. Some appear to be produced by the osteocytes. The density, distribution and extensive communication network of osteocytes make them particularly well structured to function as detectors of mechanical strain by sensing fluid movement within the bone canaliculi. They can direct the formation of new bone by activating lining cells to differentiate in preosteoblasts. ${ }^{44} \mathrm{~A}$ key molecule implicated in this mechanotransduction process appears to be sclerostin, the product of the SOST gene. ${ }^{45}$ Patients with sclerosteosis and high bone mass ${ }^{46}$ can have mutations in either the LRP5 or SOST gene. Sclerostin can bind and antagonize LRP5, a Wnt co-receptor that is required for bone formation in response to mechanical load. Mechanical loading can induce a marked reduction of sclerostin in both osteocytes and in the canaliculi network. ${ }^{45}$ Furthermore, evidence for a key role of this molecular pathway has been recently reported by demonstrating that administration of sclerostin monoclonal antibodies to primates leads to a dramatic increase in bone formation, trabecular thickness, radial, femoral 


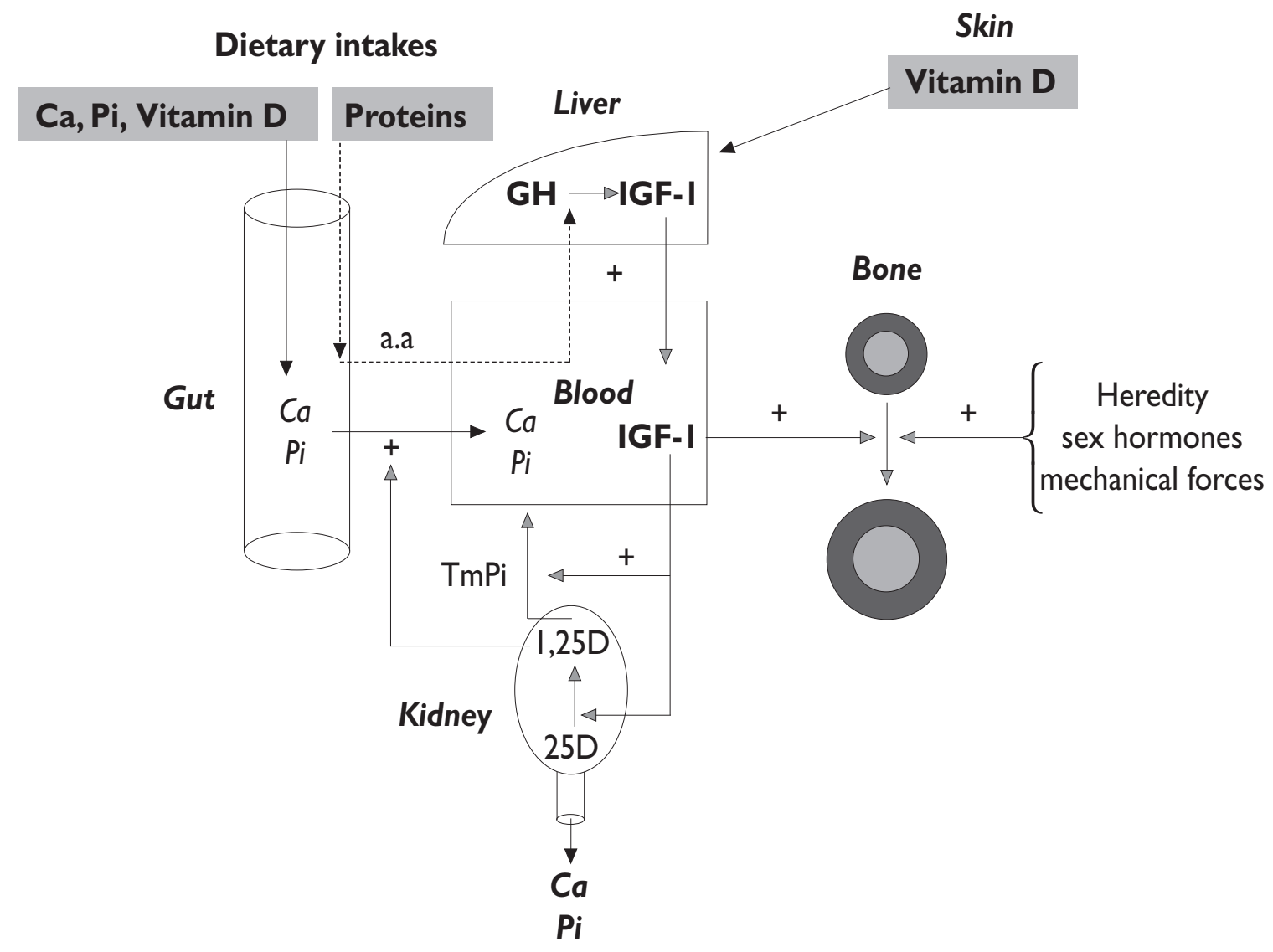

The hepatic production of IGF-I is under the positive influence of growth hormone (GH) and essential amino acids (a.a.). IGF-I exerts a direct action on bone growth. In addition, at the kidney level, IGF-I increases both the I,25-dihydroxyvitamin D (I,25D) conversion from 25-hydroxyvitamin D (25D) and the maximal tubular reabsorption of $\mathrm{Pi}(\mathrm{TmPi})$. By this dual renal action IGF-I favors a positive calcium and phosphate balance as required by the increased bone mineral accrual. See text for further details.

Figure 2. ReLATION BETWEen ESSENTIAL NUTRIENTS FOR BONE MASS ACCRUAL, INSULINE-LIKE GROWTH FACTOR-I (IGF-I), AND CALCIUM PHOSPHATE METABOLISM DURING GROWTH

and vertebral BMD as well as in bone strength. ${ }^{47}$ Therefore genes coding for the LRP5-Wnt co receptor and sclerostin are implicated in the bone anabolic response to increased mechanical strain. The mechanosensation and transduction in osteocytes still involve other factors including nitric oxide (NO), prostaglandins and ATP. ${ }^{44}$ IGF-1, membrane ion channels, integrins and connexins are also locally implicated in the response of cells to mechanical signaling in bone.

Age and optimal response to loading. Growing bones are usually more responsive to mechanical loading than adult bones. Physical activity increases bone mineral mass accumulation in both children and adolescents. However, the impact appears to be stronger before than during or after the period of pubertal maturation. ${ }^{48}$ Children and adolescents involved in various competitive sports such as gymnastics, freestyle skiing, figure or speed skating, soccer, and therefore undergoing intense training, display increased bone mineral mass gain. The greater gain in $\mathrm{aBMD}$ or BMC in young athletes compared with less active controls is preferentially localized in weight bearing bones, such as the proximal femur. Studies in adult elite athletes strongly indicate that increased bone mass gains resulting from intense physical activity during childhood and adolescence are maintained after training attenuates or even completely ceases.

Exercise during growth and fracture prevention in adulthood. The question whether the increased PBM induced by physical exercise will be maintained into old age and confer a reduction in fracture rate remains uncertain. 
A cross-sectional study of retired Australian elite soccer players suggested that this might not be the case. ${ }^{49}$ However, in another study, benefits were attenuated but not lost..$^{50}$ Thus, in ice hockey and soccer players, although exercise-induced BMD benefits during growth are partially reduced after retirement from sports, higher PBM may contribute to the lower incidence of fragility fractures observed in retired athletes beyond 60 years of age compared to matched controls. ${ }^{50}$

Moderate exercise for public health program. In the perspective of public health programs aimed at increasing bone mineral mass gain in children and adolescents, it is obvious that only physical exercise of moderate intensity, duration and frequency, but which would still be effective, can be taken into consideration. In children, prepubertal individuals or those at an early stage of sexual maturation, several interventions implemented within the school curriculum indicate that moderate exercise can impact positively on bone development. Nevertheless, it remains uncertain to what extent the greater aBMD gain in response to moderate and readily accessible weight-bearing exercise is associated with a commensurate increase in bone strength. The magnitude of benefit in terms of bone strength will depend upon the nature of the structural change. An effect consisting primarily of an increased periosteal apposition and consecutive diameter will confer greater mechanical resistance than a response limited to the endosteal apposition rate leading essentially to a reduction in the endocortical diameter.

Skeletal site specificity. Recent studies suggest site-specific differences in how the pre-pubertal skeleton develops in response to repetitive loading. ${ }^{51}$ At some sites, such as the tibia diaphysis, loading will result in geometrical changes with larger bone and greater cortical area, whereas at sites consisting predominantly of trabecular tissue, such as the distal radius and tibia, physical activity may increase the volumetric mineral density. ${ }^{51}$ Quantitative bone structural analysis in children and adolescents ${ }^{3}$ will provide a clearer assessment of the actual effects of mechanical loading components, such as intensity, duration and frequency, of various types of exercises on the size, geometry and mineral density of cortical and trabecular bones in children and adolescents.

Role of energy intake and muscle mass development. In healthy subjects, the energy intake is adjusted to increased physical activity. Hence it is difficult to ascribe the additional gain in bone mass to mechanical loading alone. Indeed, nutrients such as calcium and proteins, that are usually consumed in various amounts in relation to physical activity, could substantially contribute to the positive effect on bone mass acquisition. The in- dependent mechanical contribution can be measured by the differential effect observed according to the skeletal sites solicited. However, the best evidence of the distinct effect of mechanical loading from concomitant increase in nutritional intakes is provided by studies on the use of rackets, as determined by measuring the difference between loaded and unloaded arms.

It has been suggested that the exercise-induced gain in bone mass, size and strength essentially results from an adaptation secondary to the increase in muscle mass and strength. ${ }^{52}$ This model has more recently been challenged by several observations demonstrating that bone growth can be dissociated from muscle development. 53,54

Negative impact of intensive physical exercise. Impaired bone mass acquisition can occur when intensive physical activity leads to hypogonadism and low body mass. ${ }^{55}$ Both nutritional and hormonal factors probably contribute to this impairment. Intake of energy, protein and calcium may be inadequate as athletes go on diets to maintain an idealized physique for their sport. Intensive training during childhood may contribute to a later onset and completion of puberty. Hypogonadism, as expressed by the occurrence of oligomenorrhea or amenorrhea, can lead to bone loss in females who begin training intensively after menarche. ${ }^{55}$

\section{Nutrition: The differential impact of calcium}

The extent to which variations in the intake of certain nutrients by healthy, apparently well-nourished, children and adolescents affect bone mass accumulation, particularly at sites susceptible to osteoporotic fractures, has received increasing attention over the last 15 years. Most studies have focused on the intake of calcium. However, other nutrients such as proteins, which are not discussed in this review, should also be considered.

In most regions of the world, the supply of calcium is sufficient to avoid the occurrence of clinically manifest bone disorders during growth. Nevertheless, by securing adequate calcium intake, provided the skin and food supply of vitamin $\mathrm{D}$ is adequate, it is expected that bone mass gain can be increased during infancy, childhood and adolescence and thereby optimal PBM can be achieved. The prevention of adult osteoporotic fractures is the main reason for this widespread preoccupation.

Calcium recommendations. International and national agencies have adopted recommendations for calcium intake from infancy to the last decades of life. Decisions from these recommending bodies can be based on either calcium balance, allowing estimations to be made re- 
garding maximal retention, or on a factorial method that calculates from available data on calcium accretion and endogenous losses modified by fractional absorption. Observational and interventional studies are also taken into consideration. The recommendations vary widely among regional agencies ${ }^{56}$ (table I). Thus, for children aged 6-10 years, the recommended daily calcium intakes are set at 500,700, 800, and up to $1200 \mathrm{mg}$, in the United Kingdom, the Nordic European countries, France and the United States of America, respectively. For female adolescents aged 11-17 they are set at 800,900, 1200 and up to $1500 \mathrm{mg}$ / day in the same geographical regions, respectively. Variability in calcium intake recommendations can be explained partly by the discrepant results obtained in observational and interventional studies. Epidemiological studies. Retrospective epidemiological data obtained in women aged 20-49 years, indicated that milk consumption during childhood and adolescence can be positively correlated to bone mineral mass. ${ }^{57}$ In some but not all observational studies carried out during childhood and adolescence, a positive correla- tion between dietary calcium and bone mineral mass was reported. ${ }^{58,59}$ In our own longitudinal prospective observational study, a significant positive relationship between total calcium intakes, as determined by two 5-day diaries and bone mass accrual was found in the pubertal subgroup P1-P4, but not in the P5 subgroup. ${ }^{59}$ Furthermore, when results were analyzed by taking into account the influence of age and pubertal maturation, the relationship between the absolute values of calcium intake and the gain in the BMD Z-score suggested that calcium might be more important before than during pubertal maturation. ${ }^{59}$

Interventional studies. Several calcium intervention studies have been carried out in children and adolescents. See for review. ${ }^{58,60}$ Overall these studies indicated a greater bone mineral mass gain in children and adolescents receiving calcium supplementation over periods varying from 12 to 36 months (table II). Nevertheless, the response appears to vary markedly according to several factors including the skeletal sites examined, the stage of pubertal maturation, the basal nutritional conditions,

Table I

Dietary Calcium Reference Values For Toddlers, Children and Adolescents

\begin{tabular}{|c|c|c|c|c|c|c|c|c|c|c|}
\hline \multirow{2}{*}{ Age Group years } & \multicolumn{10}{|c|}{ Country } \\
\hline & A/G/S RNI & UK RNI & UK LRNI & EU PRI & French ANC & Nordic NR & USA RDA & Canadian RNI & USA/Canadian Al & Aust/NZ RDI \\
\hline I-3 & 600 & 350 & 200 & 400 & 600 & 600 & 800 & $500-550$ & 500 & 700 \\
\hline $4-6$ & 700 & 450 & 275 & 400 & 700 & 600 & 800 & 600 & 800 & 800 \\
\hline \multirow[t]{2}{*}{$7-10$} & 900 & 550 & 325 & 550 & $700(7-9)$ & 700 & 800 & $700(7-9)$ & $800(7-10)$ & $900 \mathrm{~F}(8-\mathrm{II})$ \\
\hline & & & & & & & & & $1300(9-10)$ & $800 \mathrm{M}(8-\mathrm{II})$ \\
\hline \multirow[t]{2}{*}{ II-14 M } & $1100-1200$ & 1000 & 325 & 1000 & $1000(10-12)$ & 900 & $1200-1500$ & $900(10-12)$ & 1300 & $1200(12-15)$ \\
\hline & & & & & $1200(\mid 3-14)$ & & & $1100(13-15)$ & & \\
\hline \multirow[t]{2}{*}{ II-I4 F } & $1100-1200$ & 800 & 325 & 800 & $1000(10-12)$ & 900 & $1200-1500$ & $1100(10-12)$ & 1300 & $1000(12-15)$ \\
\hline & & & & & $1200(\mid 3-14)$ & & & $1000(13-15)$ & & \\
\hline $15-18 \mathrm{M}$ & 1200 & 1000 & 480 & 1000 & 1200 & 900 & $1200-1500$ & $900(16-18)$ & 1300 & $1000(16-18)$ \\
\hline $15-18 \mathrm{~F}$ & 1200 & 800 & 450 & 800 & 1200 & 900 & $1200-1500$ & $700(16-18$ & 1300 & $800(16-18)$ \\
\hline
\end{tabular}

Values are in $\mathrm{mg}$ per day. $\mathrm{F}=$ Females $\mathrm{M}=$ Males. Subgroup year ranges are indicated in parenthesis

Adapted from : a) Valeurs de référence pour les apports nutritionnels. Ière Ed. Société Suisse de Nutrition 2002. b) Departement of Health Nutrition and Bone Health : with particular reference to calcium and vitamin D. Report on Health and Social Subjects 1998; 49. c) World Health Organization. Prevention and management of osteoporosis. Report of a scientific group.WHO Technical Report Series 2003;92I

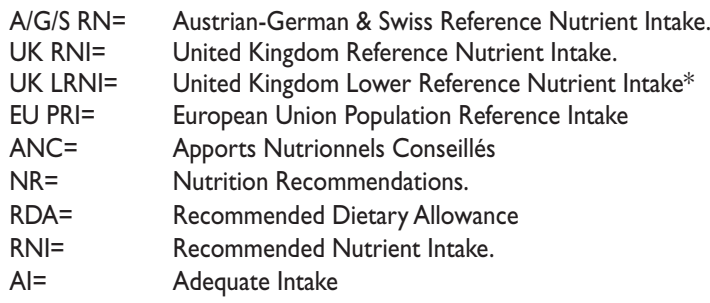

* A nutrient intake level notionally representing 2 SD below the estimated average requirement (EAR). People habitually having intakes less than the LRNI will almost certainly be deficient 
Table II

\section{Calcium Intervention Trials. Annualized \% Differences in BMD or BMC} between Calcium Supplemented and Placebo Groups

\begin{tabular}{|c|c|c|c|c|c|c|c|c|c|}
\hline $\begin{array}{l}\text { Trial* } \\
\quad \text { (Calcium salt - mg/d) }\end{array}$ & $\begin{array}{l}\text { Age } \\
\text { (yrs) }\end{array}$ & Sex & $n$ & $\begin{array}{l}\text { Duration } \\
\text { (months) }\end{array}$ & $\begin{array}{l}\text { Spontaneous Ca intake } \\
(\mathrm{mg} / \mathrm{d})\end{array}$ & $\begin{array}{l}\text { Midradius } \\
\text { BMD/BMC }\end{array}$ & $\begin{array}{c}L S \\
B M D / B M C\end{array}$ & $\begin{array}{c}F N \\
B M D / B M C\end{array}$ & $\begin{array}{c}\text { FS } \\
B M D / B M C\end{array}$ \\
\hline \multicolumn{10}{|l|}{ Matkovic et al. 1990} \\
\hline (Ca carbonate or milk $2 \%$ fat -900 ) & 14 & $\mathrm{~F}$ & 31 & 24 & 1017 & $1.0^{\ddagger}$ & 0.0 & NA & NA \\
\hline \multicolumn{10}{|l|}{ Johnston et al. 1992} \\
\hline \multirow[t]{2}{*}{ (Citrate malate -1000$)$} & $6-14$ & Twins (all) & 90 & 36 & 900 & 0.8 & 0.2 & 0.1 & NA \\
\hline & \multicolumn{3}{|c|}{ Prepubertal } & & & & $1.7^{\S}$ & $0.9 \S$ & 0.4 \\
\hline \multicolumn{10}{|l|}{ Lloyd et al. 1993} \\
\hline (Citrate malate -350$)$ & $11-13$ & $\mathrm{~F}$ & 94 & 18 & 960 & NA & $2.0 \S / 1.6^{\#}$ & NA & NA \\
\hline \multicolumn{10}{|l|}{ Lee et al. 1994} \\
\hline (Calcium carbonate - 300) & $6-8$ & $\mathrm{~F} / \mathrm{M}$ & 162 & 18 & 280 & I.I\# & 1.2 & 0.4 & NA \\
\hline \multicolumn{10}{|l|}{ Lee et al. 1995} \\
\hline (Calcium carbonate - 300) & $6-8$ & $\mathrm{~F} / \mathrm{M}$ & 84 & 18 & 565 & $\mathrm{NA} / 0.7^{\ddagger}$ & $0.6 / 2.7^{\S}$ & NA & NA \\
\hline \multicolumn{10}{|l|}{ Bonjour et al. 1997} \\
\hline (Milk extracted Ca-Pi salt - 850) & $6-9$ & $\mathrm{~F}$ & 144 & 12 & 900 & $1.7^{\S}$ & 0.4 & 1.0 & $1.2^{\S}$ \\
\hline \multicolumn{10}{|l|}{ Nowson et al. 1997} \\
\hline (Lactate gluconate - 1000 ) & $10-17$ & F, twins & 74 & 18 & 730 & NA & $1.5^{\S}$ & 0.9 & NA \\
\hline \multicolumn{10}{|l|}{ Dibba et al. 2000} \\
\hline (Ca carbonate -700$)$ & $8-12$ & $\mathrm{~F} / \mathrm{M}$ & 160 & 12 & 340 & $3.9 \neq / 2.1$ & NA & NA & NA \\
\hline \multicolumn{10}{|l|}{ Cameron et al. 2004} \\
\hline (Ca carbonate- 1200$)$ & $8-17$ & F, twins & 48 & 24 & 715 & NA & 0.7 & -0.3 & NA \\
\hline \multicolumn{10}{|l|}{ Prentice et al. 2005} \\
\hline (Ca carbonate- 1000$)$ & $16-18$ & M & 143 & 13 & 1200 & $0.3 / 0.8$ & $1.0 / 2.5^{\&}$ & $1.5^{\S} / 2.4^{\S}$ & NA \\
\hline \multicolumn{10}{|l|}{ Chevalley et al. 2005} \\
\hline (Milk extracted Ca-Pi salt - 850) & $6-8$ & M & 235 & 12 & 750 & $0.7 / 0.7$ & $-0.3 / 0.0$ & $0.0 /-0.1$ & $1.3^{2} / 1.3$ \\
\hline \multicolumn{10}{|l|}{ Iuliano-Burns et al. 2006} \\
\hline (Milk minerals or Ca carbonate - 800) & $5-11$ & $F / M$ & 99 & 10 & 800 & NA & $\mathrm{NA} / 0 . \mathrm{I}$ & NA & $\mathrm{NA} / 0.2$ \\
\hline
\end{tabular}

* Analysis in Intention-to-Treat except in trials from Johnston et al.1992, Lloyd et al.1993, Nowson et al.1997 and Cameron et al.2004

\# by single photon absorptiometry

$\S p<0.05$

$\# p<0.10$

\& $p<0.01$

${ }^{\neq} p<0.001$

$\mathrm{F}=$ Females

$M=$ Males

NA $=$ Not Available

LS= Lumbar Spine

$\mathrm{FN}=$ Femoral Neck

$\mathrm{FS}=$ Femoral Shaft

References: Matkovic V, et al. Am J Clin Nutr 1990;52(5):878-888; Johnston CC, et al. N Engl J Med 1992;327(2):82-7; Lloyd T et al.JAMA 1993;270(7):84I-4. Lee WT et al. Am J Clin Nutr 1994;60(5):744-50 and Br J Nutr 1995;74(I): I25-39; Bonjour JP et al. J Clin Invest 1997;99(6): I287-94; Nowson CA et al. Osteoporos Int 1997;7(3):2 19-25; Dibba B et al. Am J Clin Nutr 2000;7I (2):544-9; Cameron MA et al.J Clin Endocrinol Metab 2004;89(I0):49I6-22; Prentice A et al. J Clin Endocrinol Metab 2005;90(6):3153-6I; Chevalley T et al. J Clin Endocrinol Metab 2005;90(6):3342-9. luliano-Burns S et al. Osteoporos Int 2006; I7(I2): 1794-800

i.e. spontaneous calcium and protein intakes, the level of physical activity and the genetic background Differential skeletal site responsiveness. The benefit of supplemental calcium was usually greater in the appendicular that in the axial skeleton. ${ }^{58,60}$ Thus, in prepubertal children, calcium supplementation is more effective on cortical appendicular bone (radial and femoral diaphysis) than on axial trabecular rich bone (lumbar spine) or in the proximal femur.$^{58,60}$

Influence of stage of pubertal maturation. In agreement with our longitudinal observation in healthy subjects aged 8 to 19 years (figure 6), the skeleton appears to be more 
responsive to calcium supplementation before the onset of pubertal maturation than during the peripubertal period. ${ }^{58,60}$ Randomized placebo-controlled trials in twins are particularly informative in this regard.$^{61}$ Indeed, the co-twin design to test the effect of calcium supplementation confers a substantial advantage in statistical power, compared with intervention studies in unrelated individuals. Two co-twin studies strongly suggest that increasing calcium intake after the onset of pubertal maturation above a daily spontaneous intake of about $800-900 \mathrm{mg}$ does not exert a significant positive effect on bone mineral mass acquisition. This contrasts to the widespread intuitive belief that the period of pubertal maturation with its acceleration of bone mineral mass accrual would be the most attractive time for enhancing calcium intake well above the prepubertal requirements. As described above efficient adaptive mechanisms secure an adequate bone mineral economy in response to the increased demand of the peripubertal growth spurt. ${ }^{61}$ Thanks to these adaptive processes, one can infer that the dependency on environmental mineral supply to secure bone growth demand is not necessarily increased during the peripubertal period as compared to the years preceding the onset of sexual maturation. ${ }^{61}$ Spontaneous calcium intake. As intuitively expected, the benefit observed at the end of intervention is particularly substantial in children with a relatively low calcium intake. ${ }^{58,60}$ In 8-year-old prepubertal girls with relatively low spontaneous calcium intake, increasing the calcium intake resulted in an additionnal gain by about 0.25 $\mathrm{SD}$ as compared to the placebo group after one year of supplementation. In contrast, the additional gain was minimal in those girls with a relatively high calcium intake. ${ }^{60}$ Therefore, below a certain threshold in the spontaneous supply it is quite likely that increasing the calcium intake can "push upward" the bone individual growth trajectory and thereby positively influence the value of PBM. According to the "programming" concept, environmental stimuli during critical periods of early development can provoke long-lasting modifications in structure and function of various biological systems. ${ }^{63}$ Interventions limited to the first period of life may modify the trajectory of bone mass accrual. ${ }^{64}$ This concept received some support in relation with calcium economy since vitamin $\mathrm{D}$ given in physiological doses $(400 \mathrm{IU}=10 \mu \mathrm{g})$ to female infants for an average of one year was associated with a significant increase in aBMD measured at the age of 7-9 years..$^{65}$ In this study, the aBMD difference between the vitamin D-supplemented and non-supplemented infants was most significant at the femoral neck, trochanter and radial metaphysis. ${ }^{65}$ Calcium intake and physical activity interaction. The possibility that physical activity could modulate the bone response to dietary calcium supplementation during growth has been considered in infants, children and adolescents. Overall, the results suggest an interaction: the higher the calcium intake, the more positive the effect that increased physical activity exerts on bone growth. At moderately low calcium intake, the effect may not be positive. Thus, in a longitudinal study in infants 6-18 months of age, i.e. during rapid bone growth, loading of the skeleton was associated with a reduced increase in total body BMC in the presence of a moderately low calcium intake. In young children aged 3-5 years, either calcium supplement or gross motor activity increased bone mass accrual as compared to either placebo or fine motor activity ${ }^{66}$ Furthermore, the bone response to calcium supplement was greater in children with gross than fine physical activity. ${ }^{66}$ In another study in 8-9 yearold girls, greater gains in bone mass at weight-bearing skeletal sites were observed when moderate exercise was combined with calcium supplementation. ${ }^{66}$ Thus, the positive interaction of calcium intake and physical activity appears to be region-specific. This regional specificity suggests that the effect of physical activity alone or combined with relatively high calcium supply is not merely due to an indirect influence on the energy intake, which in turn would positively affect bone mass acquisition.

Other unresolved issues. It has not been established whether the type of calcium salt used to supplement diets may modulate the nature of the bone response. The observation that calcium supplementation can increase bone size, at least transiently, has been observed using either milk extracted calcium-phosphate as well as calcium carbonate salt. ${ }^{58,60}$ It is interesting to note that an effect on bone size has been observed in response to whole milk supplementation. ${ }^{68}$ In this type of intervention, the effect could be due to other nutrients, or their association with calcium, such as milk-proteins. Another uncertainty is the question of whether gains observed by the end of the intervention are maintained or lost after discontinuation of calcium supplementation. A clear answer to this question requires long term follow up, since sustained gain even on bone mass and size may be transient, possibly resulting from some indirect influence of calcium supplementation on the tempo of pubertal and thereby bone maturation. ${ }^{42,69}$

Calcium intake: how much eventually to recommend from prepuberty to end of adolescence? The observational and interventional studies discussed above illustrate the numerous factors that can modulate the bone response to calcium intake. This foregoing analysis may, at least in part, explain the difficulty to reach a scientifically based worldwide consensus on dietary allowance recommendation for children and adolescents. Nevertheless, tak- 
ing into account both the results of all studies as well as our knowledge on the physiology of calcium and bone metabolism, particularly on the adaptive mechanisms operating during the peripubertal period, ${ }^{61}$ it appears reasonable and safe to recommend food intake that would provide about $1000 \mathrm{mg}$ of calcium per day from prepuberty to the end of adolescence.

\section{References}

I.World Health Organization.Assessment of fracture risk and its application to screening for postmenopausal osteoporosis. Report of a WHO study group.WHO Tech Rep Ser: 843; 1994.

2. Briot $K$, Roux C. What is the role of DXA, QUS and bone markers in fracture prediction, treatment allocation and monitoring? Best Pract Res Clin Rheumatol 2005;19(6):951-964.

3. Specker BL, Schoenau E. Quantitative bone analysis in children: current methods and recommendations. J Pediatr 2005; I46(6):726-73I.

4. Bonjour JP, Theintz G, Law F, Slosman D, Rizzoli R. Peak bone mass. Osteoporos Int 1994;4 Suppl I:7-13.

5. Ferrari S, Rizzoli R, Slosman D, Bonjour JP. Familial resemblance for bone mineral mass is expressed before puberty.J Clin Endocrinol Metab 1998;83(2):358-36।.

6. Gilsanz V, Skaggs DL, Kovanlikaya A, Sayre J, Loro ML, Kaufman F, et al. Differential effect of race on the axial and appendicular skeletons of children.J Clin Endocrinol Metab 1998;83(5): I420-I427.

7. Seeman E. Pathogenesis of bone fragility in women and men. Lancet 2002;359(9320):184|-1850.

8. Theintz G, Buchs B, Rizzoli R, Slosman D, Clavien H, Sizonenko PC, et al. Longitudinal monitoring of bone mass accumulation in healthy adolescents: Evidence for a marked reduction after 16 years of age at the levels of lumbar spine and femoral neck in female subjects.

J Clin Endocrinol Metab 1992;75(4):1060-1065.

9. Fournier PE, Rizzoli R, Slosman DO, Buchs B, Bonjour JP. Relative contribution of vertebral body and posterior arch in female and male lumbar spine peak bone mass. Osteoporos Int 1994;4(5):264-272. 10. Gilsanz V, Loro ML, Roe TF, Sayre J, Gilsanz R, Schulz EE.Vertebral size in elderly women with osteoporosis. Mechanical implications and relationship to fractures.J Clin Invest 1995;95(5):2332-2337.

II. Naganathan V, Sambrook P. Gender differences in volumetric bone density: a study of opposite-sex twins. Osteoporos Int 2003;14(7):564-569. 12. Fournier PE, Rizzoli R, Slosman DO, Theintz G, Bonjour JP. Asynchrony between the rates of standing height gain and bone mass accumulation during puberty. Osteoporos Int 1997;7(6):525-532.

13. Landin LA. Fracture patterns in children. Analysis of 8,682 fractures with special reference to incidence, etiology and secular changes in a Swedish urban population 1950-1979.Acta Orthop Scand Suppl 1983;202:1-109.

14. Bailey DA, Wedge JH, McCulloch RG, Martin AD, Bernhardson SC. Epidemiology of fractures of the distal end of the radius in children as associated with growth.J Bone Joint Surg 1989;7|(8): I225-I23I.

15. Ferrari SL, Chevalley T, Bonjour JP, Rizzoli R. Childhood fractures are associated with decreased bone mass gain during puberty: An early marker of persistent bone fragility? J Bone Miner Res 2006;2I (4):50 I-507. 16. Bonjour JP, Chevalley T. Pubertal timing, peak bone mass and fragility fracture risk. BoneKey-Osteovision. 2007;4:30-48. Available from: http:// www.bonekey-ibms.org/cgi/content/full/ibmske;4/2/30.
I7. Gilsanz V, Gibbens DT, Carlson M, Boechat MI, Cann CE, Schulz EE. Peak trabecular vertebral density: a comparison of adolescent and adult females. Calcif Tissue Int 1988;43(4):260-262.

18. Davis JW, Grove JS, Ross PD, Vogel JM, Wasnich RD. Relationship between bone mass and rates of bone change at appendicular measurement sites. J Bone Miner Res 1992;7(7):719-725.

19. Buchs B, Rizzoli R, Slosman D, Nydegger V, Bonjour JP. Densité minérale osseuse de la colonne lombaire, du col et de la diaphyse fémoraux d'un échantillon de la population genevoise. Schweiz Med Wochenschr 1992;25; 122(30):I I29-1। 36.

20. Melton LJ, 3rd, Atkinson EJ, Khosla S, Oberg AL, Riggs BL. Evaluation of a prediction model for long-term fracture risk.J Bone Miner Res. 2005;20(4):55I-556.

21. Hernandez CJ, Beaupre GS, Carter DR.A theoretical analysis of the relative influences of peak $B M D$, age-related bone loss and menopause on the development of osteoporosis. Osteoporos Int 2003;14(10):843-847. 22. Duan Y,Wang XF, Evans A, Seeman E. Structural and biomechanical basis of racial and sex differences in vertebral fragility in Chinese and Caucasians. Bone 2005;36(6):987-998.

23. Zebaze RM, Jones A, Knackstedt M, Maalouf G, Seeman E. Construction of the femoral neck during growth determines its strength in old age.J Bone Miner Res 2007;22(7): 1055-1061.

24. Cummings SR, Black DM, Nevitt MC, Browner W, Cauley J, Ensrud $\mathrm{K}$, et al. Bone density at various sites for prediction of hip fractures. The Study of Osteoporotic Fractures Research Group. Lancet 1993;9;34I(8837):72-75.

25. Marshall D, Johnell O,Wedel H. Meta-analysis of how well measures of bone mineral density predict occurrence of osteoporotic fractures. Br Med J 1996;18;312(704I):1254-1259.

26. Seeman E, Hopper JL, Bach LA, Cooper ME, Parkinson E, McKay J, et al. Reduced bone mass in daughters of women with osteoporosis. N Engl J Med 1989;2;320(9):554-558.

27. Cohen-Solal ME, Baudoin C, Omouri M, Kuntz D, De Vernejoul MC. Bone mass in middle-aged osteoporotic men and their relatives: familial effect. J Bone Miner Res 1998;13(I2):1909-1914.

28. Eisman JA. Genetics of osteoporosis. Endocr Rev 1999;20(6):788-804. 29. Peacock M, Turner CH, Econs MJ, Foroud T. Genetics of osteoporosis. Endocr Rev 2002;23(3):303-326.

30. Ferrari SL. Osteoporosis: a complex disorder of aging with multiple genetic and environmental determinants. World Rev Nutr Diet 2005;95:35-5I.

3I. Bonjour JP, Chevalley T, Rizzoli R, Ferrari S. Gene-environment interactions in the skeletal response to nutrition and exercise during growth. Med Sport Sci 2007;51:64-80.

32.Vanderschueren D,Vandenput L, Boonen S, Lindberg MK, Bouillon R, Ohlsson C.Androgens and bone. Endocr Rev 2004;25(3):389-425.

33.Vanderschueren D, Vandenput L, Boonen S. Reversing sex steroid deficiency and optimizing skeletal development in the adolescent with gonadal failure. Endocr Dev 2005;8:150-165.

34. Garn SM.The earlier gain and later loss of cortical bone: Nutritional perspectives. In:Thomas CC, ed.: Springfield 1970:3-120.

35. Ribot C, Pouilles JM, Bonneu M,Tremollieres F.Assessment of the risk of post-menopausal osteoporosis using clinical factors. Clin Endocrinol (Oxf) 1992;36(3):225-228.

36. Tuppurainen M, Kroger H, Saarikoski S, Honkanen R,Alhava E. The effect of gynecological risk factors on lumbar and femoral bone mineral density in peri- and postmenopausal women. Maturitas 1995;2I(2): I37-145. 37. Melton LJ, 3rd. Epidemiology of spinal osteoporosis. Spine 1997; 15;22(24 Suppl):S2-SII.

38. Johnell O, Gullberg B, Kanis JA,Allander E, Elffors L, Dequeker J, et al. Risk factors for hip fracture in European women: the MEDOS Study. 
Mediterranean Osteoporosis Study.J Bone Miner Res 1995; I0(II): I802-18I5.

39. Ito M, Yamada M, Hayashi K, Ohki M, Uetani M, Nakamura T. Relation of early menarche to high bone mineral density. Calcif Tissue Int 1995;57(I): I I-4.

40. Fujita Y, Katsumata K, Unno A, Tawa T, Tokita A. Factors affecting peak bone density in Japanese women. Calcif Tissue Int 1999;64(2): 107-I I I. 4I. Kindblom JM, Lorentzon M, Norjavaara E, Hellqvist A, Nilsson S, Mellstrom D, et al. Pubertal timing predicts previous fractures and BMD in young adult men: the GOOD study.J Bone Miner Res 2006;2I(5):790-795 42. Chevalley T, Rizzoli R, Hans D, Ferrari S, Bonjour JP. Interaction between calcium intake and menarcheal age on bone mass gain: An eightyear follow-up study from prepuberty to postmenarche.J Clin Endocrinol Metab 2005;90(I):44-5I.

43. Caverzasio J, Bonjour JP. Characteristics and regulation of Pi transport in osteogenic cells for bone metabolism. Kidney Int 1996;49(4):975-980. 44. Robling AG, Castillo AB, Turner CH. Biomechanical and molecular regulation of bone remodeling. Annu Rev Biomed Eng 2006;8:455-498. 45. Robling AG, Bellido TM, Turner CH. Mechanical loading reduced osteocyte expression of sclerostin protein. J Bone Miner Res 2006;2I(Suppl I):S72.

46. Gardner JC, van Bezooijen RL, Mervis B, Hamdy NA, Lowik $\mathrm{CW}$, Hamersma $\mathrm{H}$, et al. Bone mineral density in sclerosteosis; affected individuals and gene carriers.J Clin Endocrinol Metab 2005 Dec;90(12):6392-6395.

47. Ominsky M, Stouch B, Doellgast G, Gong G, Cao J, Gao Y, et al. Aministration of sclerostin antibodies to female cynomolgus monkeys results in increased bone formation, bone mineral density and bone strength.J Bone Miner Res 2006;2I(Suppl I):S44.

48. Bass SL, Saxon L, Daly RM, Turner CH, Robling AG, Seeman E, et al. The effect of mechanical loading on the size and shape of bone in pre-, peri-, and postpubertal girls: a study in tennis players.J Bone Miner Res 2002; 17(I2):2274-2280.

49. Karlsson MK, Linden C, Karlsson C, Johnell O, Obrant K, Seeman E. Exercise during growth and bone mineral density and fractures in old age. Lancet 2000; 5;355(9202):469-470.

50. Nordstrom A, Karlsson C, Nyquist F, Olsson T, Nordstrom P, Karlsson M. Bone loss and fracture risk after reduced physical activity.J Bone Miner Res 2005;20(2):202-207.

5I.Ward KA, Roberts SA, Adams JE, Mughal MZ. Bone geometry and density in the skeleton of pre-pubertal gymnasts and school children. Bone 2005;36(6): 1012-1018.

52. Schoenau E, Frost HM. The "muscle-bone unit" in children and adolescents. Calcif Tissue Int 2002;70(5):405-407.

53. Daly RM, Saxon L, Turner CH, Robling AG, Bass SL. The relationship between muscle size and bone geometry during growth and in response to exercise. Bone 2004;34(2):28I-287.
54. Ducher G, Courteix D, Meme S, Magni C,Viala JF, Benhamou CL. Bone geometry in response to long-term tennis playing and its relationship with muscle volume: a quantitative magnetic resonance imaging study in tennis players. Bone 2005;37(4):457-466.

55. Warren MP, Goodman LR. Exercise-induced endocrine pathologies. J Endocrinol Invest 2003;26(9):873-878.

56. World Health Organization. Prevention and management of osteoporosis. Report of a scientific group.WHO Technical Report Series: 921;2003.

57. Kalkwarf HJ, Khoury JC, Lanphear BP. Milk intake during childhood and adolescence, adult bone density, and osteoporotic fractures in US women. Am J Clin Nutr 2003;77(I):257-265.

58. Wosje KS, Specker BL. Role of calcium in bone health during childhood. Nutr Rev 2000;58(9):253-268.

59. Bonjour JP, Rizzoli R. Bone acquisition in adolescence. In: Marcus R, Feldman D, Kelsey J, eds. Osteoporosis. San Diego:Academic Press 200I:62I-638.

60. Bonjour JP,Ammann P, Chevalley T, Ferrari S, Rizzoli R. Nutritional aspects of bone growth: An overview. In: New S, Bonjour JP, eds. Nutritional aspects of bone health. Cambridge, UK:The Royal Society of Chemistry, 2003:III-27.

6I. Bonjour JP. Is peripuberty the most opportune time to increase calcium intake in healthy girls ? BoneKey-Osteoporosis 2005;2:6-I I. Available from: http://www.bonekey-ibms.org/cgi/content/full/ibmske;2/3/6. 62. Bonjour JP, Carrie AL, Ferrari S, Clavien H, Slosman D, Theintz G, et al. Calcium-enriched foods and bone mass growth in prepubertal girls: a randomized, double-blind, placebo-controlled trial. J Clin Invest 1997;15;99(6): I287-1 294.

63. Barker DJ. Intrauterine programming of adult disease. Mol Med Today 1995; I(9):418-423.

64. Cooper C, Fall C, Egger P, Hobbs R, Eastell R, Barker D. Growth in infancy and bone mass in later life. Ann Rheum Dis 1997;56(I): 17-21. 65. Zamora SA, Rizzoli R, Belli DC, Slosman DO, Bonjour JP.Vitamin D supplementation during infancy is associated with higher bone mineral mass in prepubertal girls.J Clin Endocrinol Metabol 1999;84(I2):454I-4544. 66. Specker B, Binkley T. Randomized trial of physical activity and calcium supplementation on bone mineral content in 3- to 5-year-old children. J Bone Miner Res 2003;18(5):885-892.

67. Iuliano-Burns S, Saxon L, Naughton G, Gibbons K, Bass SL. Regional specificity of exercise and calcium during skeletal growth in girls: A randomized controlled trial.J Bone Miner Res 2003;18(I):156-162. 68. Cadogan J, Eastell R, Jones N, Barker ME. Milk intake and bone mineral acquisition in adolescent girls: randomised, controlled intervention trial. Br Med J 1997;315(71 I8):1255-1260.

69. Prentice A, Ginty F, Stear SJ, Jones SC, Laskey MA, Cole TJ. Calcium supplementation increases stature and bone mineral mass of 16- to I8year-old boys. J Clin Endocrinol Metabol 2005;90(6):3153-3I6I. 